\title{
Combination of enzymatic procedures with multicomponent condensations*
}

\author{
Ryszard Ostaszewski ${ }^{1,2, \mp}$, David E. Portlock ${ }^{3}$, Anna Fryszkowska ${ }^{2}$, \\ and Katarzyna Jeziorska ${ }^{2}$
}

${ }^{1}$ Institute of Organic Chemistry PAS, 01-224 Warsaw, Kasprzaka 44/52, Poland;

${ }^{2}$ Faculty of Chemistry, Warsaw University of Technology, 00-664 Warsaw, Noakowskiego 3, Poland; ${ }^{3}$ Combinatorial Chemistry Section, Procter \& Gamble Pharmaceuticals, Health Care Research Center, 8700 Mason Montgomery Road, Mason, $\mathrm{OH} 45040$, USA

\begin{abstract}
A new synthetic method based on combination of enzymatic desymmetrization of 3-phenylglutaric anhydrides with multicomponent condensation is outlined. Enzymatic monoesterification of glutaric anhydrides was performed, and the derived monoacids were used as substrates for subsequent Ugi and Passerini multicomponent condensations. Both reactions were combined as two-step, one-pot processes. The choice of solvent and enzyme type has an appreciable effect on the course of reactions.
\end{abstract}

\section{INTRODUCTION}

Multicomponent condensation (MCC) is of great interest in medicinal chemistry [1]. MCCs are most useful in peptidomimetic synthesis owing to their ability to generate large numbers of compounds efficiently in one or two synthetic steps [2].

Commonly used MCCs include the Ugi [3], Passerini [4], Biginelli [5], and the Petasis boronic acid-Mannich reactions [6]. Most of these and other MCCs have been used to generate combinatorial libraries useful for pharmaceutical purposes [7].

Recently, we have shown that two different MCCs, those of Petasis and of Ugi, can be used as tandem processes, without purification of intermediate products [8]. Such two-step, one-pot syntheses, performed in good overall yield, aspire to "ideal process" [9].

Unfortunately, generation of optically active combinatorial libraries is much more difficult [10]. In most cases, different types of chiral auxiliary are used in these syntheses, which complicates the overall processes since not all auxiliaries are cheap and readily available in both enantiomeric forms. Also, two additional steps are required for introduction and efficient removal of these groups.

In classical processes for generation of optically active libraries, a racemic substrate is resolved into enantiomers using chemical or physical methods and then used as a substrate for reaction $\mathbf{1}$ and subsequent MCC (reaction 2 in Chart 1).

Chart 1 Classical processes.

\begin{tabular}{|c|c|c|c|c|c|c|}
\hline $\begin{array}{l}\text { Substrate } \\
\text { (racemic) }\end{array}$ & $\begin{array}{l}\text { Resolution into } \\
\text { enantiomers }\end{array}$ & $\begin{array}{l}\text { Substrate } \\
\text { (single enantiomer) }\end{array}$ & Reaction 1 & Product & Reaction 2 & $\begin{array}{l}\text { Final } \\
\text { Product }\end{array}$ \\
\hline
\end{tabular}

\footnotetext{
* Pure Appl. Chem. 75, 141-419 (2003). An issue of reviews and research papers based on lectures presented at the $23^{\text {rd }}$ IUPAC International Symposium on the Chemistry of Natural Products, Florence, Italy, 28 July-2 August 2002 on the theme of natural products.

${ }^{\ddagger}$ Corresponding author
} 
Our idea is based on combination of enzymatic procedures with multicomponent condensation as a one-pot, two-step reaction. We propose to use a meso reagent as substrate, which can be enzymatically desymmetrized [11] into the desired optically active product. In this way, two steps, resolution of enantiomers and reaction 1, can be combined in one step (Chart 2). In an ideal situation, the derived product should be used directly in a subsequent MCC (Chart 2). This two-step, one-pot approach is much simpler then those currently in use, and application of chiral auxiliaries is omitted. We are unaware of any precedent for combining an enzymatic procedure with an MCC.

Chart 2 Combination of enzymatic procedure with MCC.

\begin{tabular}{llllll}
\hline $\begin{array}{l}\text { Substrate } \\
(\text { meso })\end{array}$ & $\begin{array}{l}\text { Enzymatic } \\
\text { desymmetrization }\end{array}$ & Reaction 1 & Product & MCC & Final product \\
\hline
\end{tabular}

Because it is known that carboxylic acids are used as substrates in Ugi and Passerini condensations, we decided to generate these chiral reagents from respective cyclic anhydrides I. In this way, enzymatic desymmetrization would give chiral monoesters of structure II, which can be used directly, without additional purification, as substrates for MCC. This reaction sequence leads to formation of products of peptidomimetic structure for Ugi (III, X = NR4) or Passerini (III, X = O) condensations.

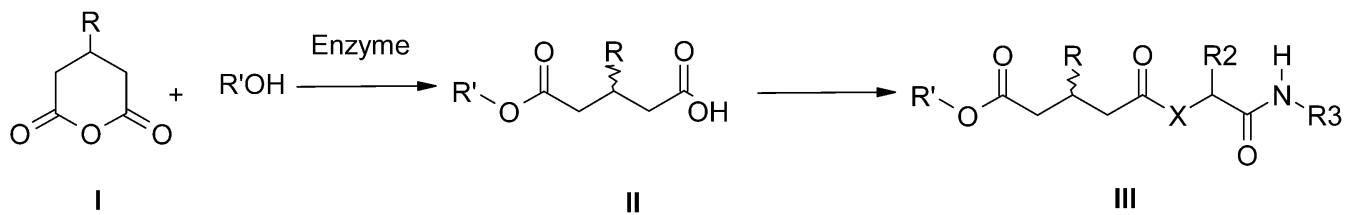

Scheme 1 General synthetic concept.

Enzymatic desymmetrizations of glutaric anhydrides I are well known [12]. Lipase-catalyzed ring-opening of meso anhydrides proceeds with high yield and good enantioselectivity in organic solvents, which is extremely important for the subsequent MCC. We proposed to use this approach for desymmetrization of 3-phenylglutaric anhydrides. This building block has been used to elaborate targets possessing interesting biological activity. For example, the chiral monomethyl ester of 3-fluorophenyl glutaric acid has been reported as a key substrate in synthesis of paroxetine hydrochloride, a selective serotonin reuptake inhibitor [13], and the chiral monoethyl ester of 3,4-dichlorophenyl glutaric acid has been used for synthesis of a neurokinin receptor antagonist [14]. Both compounds were prepared via enzymatic hydrolysis of the respective diesters.

\section{SYNTHESIS OF 3-PHENYLGLUTARIC ANHYDRIDES}

The synthesis starts with piperidine-catalyzed condensation of benzaldehydes $\mathbf{1}$ with ethyl acetyloacetate.

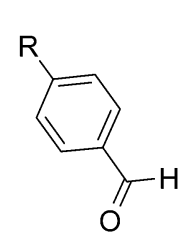

1

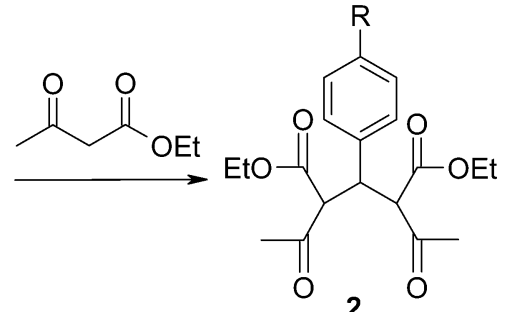

2

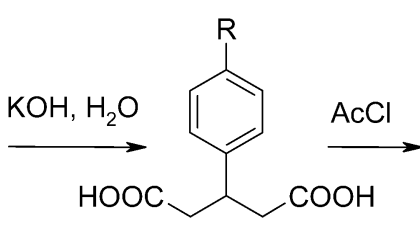

3<smiles>[R]c1ccc(C2CC(=O)OC(=O)C2)cc1</smiles>

4

Scheme 2 Synthesis of 3-phenylglutaric anhydrides. 
Reactions with benzaldehyde and 4-methoxybenzaldehyde furnished products $2 \mathbf{a}$ and $\mathbf{2 c}$ in $57 \%$ and $46 \%$ yields, respectively. In the case of 4-chlorobenzaldehyde this reaction proceeds in $95 \%$ yield. Base-catalyzed hydrolysis leads to formation of diacids 3 in 65-71\% yield. Reaction of diacids 3 with acetyl chloride is strongly influenced by phenyl ring substituents. For phenyl (3a) and 4-methoxyphenyl (3c) intermediates, acid anhydrides were obtained in 54 and $41 \%$ yields respectively. Again, for the 4-chlorophenyl diacid $\mathbf{3 b}$, reaction proceeds in very good $94 \%$ yield.

\section{ENZYMATIC DESYMMETRIZATION OF 3-PHENYLGLUTARIC ANHYDRIDES}

Based on literature data on enzymatic desymmetrization of 3-alkylglutaric anhydrides [15], 2-alkylglutaric anhydrides [16], and 2,3-dimethylglutaric anhydride [17] initially, we employed PCL and CAL-B enzymes for the desymmetrization reaction. Unfortunately, anhydrides 4 were found to be much more reactive than those mentioned above. Over 20 different enzymes were tested, but none of expected monoester of structure 5 was obtained. After many trials, we found that the immobilized enzyme Novo SP435A can be used as a catalyst for this reaction.

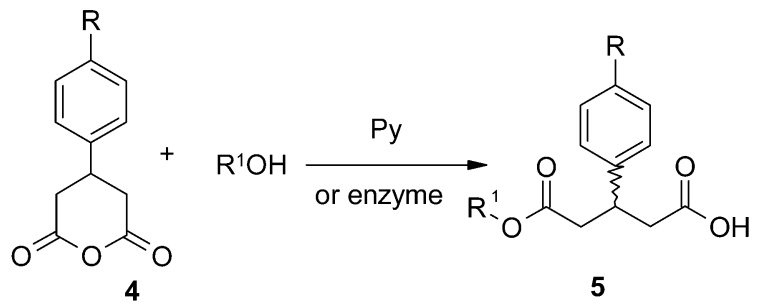

Scheme 3 Synthesis of racemic monoesters 5.

Because the course of immobilized enzymatic reactions is strongly dependent on the solvent used [18], the influence of reaction medium was studied in detail. The most important results are summarized in Table 1. In ethereal solvents, reaction proceeds with almost the same enantioselectivity, but full conversion changes from $177 \mathrm{~h}$ in diethyl ether to $43 \mathrm{~h}$ in isopropyl or tert-butyl methyl ethers (entries 1,3 , and 4 in Table 1). The optical rotation of monoethyl ester $\mathbf{5 a}[\alpha]_{D}=-9.5^{\circ}(\mathrm{c} 1.1$, benzene) was compared with the literature value $[\alpha]_{\mathrm{D}}=9.47^{\circ}$ (c 1.1, benzene) measured for the $R$ enantiomer [19], so this product was assigned $S$ configuration. Enantiomeric excess was measured by an HPLC method on Shimazu LC-6A apparatus equipped with chiral CHIRALCEL OD-H column.

Table 1 The influence of solvent on enzymatic desymmetrization of 3-phenylglutaric anhydrides (4a), catalyzed by Novo SP435A using ethanol.

\begin{tabular}{llcc}
\hline Entry & \multicolumn{1}{c}{ Solvent } & $\begin{array}{c}\text { Reaction time } \\
\text { h/days }\end{array}$ & E.e. \\
\hline 1 & diethyl ether & $114 /-$ & $7: 1(\mathrm{~S})$ \\
2 & dipropyl ether & $177 /-$ & $8: 1(\mathrm{~S})$ \\
3 & isopropyl ether & $43 /-$ & $8: 1(\mathrm{~S})$ \\
4 & tert-butyl methyl ether & $43 /-$ & $7: 1(\mathrm{~S})$ \\
5 & di-butyl ether & $73 /-$ & $7: 1(\mathrm{~S})$ \\
6 & methylene chloride & $-/ 35$ & $1: 1$ \\
7 & chloroform & $-/ 35$ & $1: 1$ \\
\hline
\end{tabular}


In the next step, the influence of enzyme type on reaction course was studied, and data are summarized in Table 2. Reactions were performed to allow full conversion. Reaction time is included in this table.

Table 2 The influence of enzyme type on desymmetrization reaction of anhydrides 4 by ethanol in isopropyl ether.

\begin{tabular}{|c|c|c|c|c|c|c|c|}
\hline \multirow[t]{2}{*}{ Entry } & \multirow[t]{2}{*}{ Lipase } & \multicolumn{2}{|c|}{$5 \mathbf{a}$} & \multicolumn{2}{|c|}{$5 \mathbf{b}$} & \multicolumn{2}{|c|}{$5 c$} \\
\hline & & $\begin{array}{l}\text { Time } \\
\text { (h/days) }\end{array}$ & $\mathrm{E}_{\mathrm{r}}$ & $\begin{array}{c}\text { Time } \\
\text { (h/days) }\end{array}$ & $\mathrm{E}_{\mathrm{r}}$ & $\begin{array}{c}\text { Time } \\
\text { (h/days) }\end{array}$ & $\mathrm{E}_{\mathrm{r}}$ \\
\hline 1 & Novozyme 435 & 61/- & $8: 1$ & $120 /-$ & $5: 1$ & $-/ 22$ & $5: 1$ \\
\hline 2 & Chirazyme L-2, C3 & 19/- & 11:1 & $-/ 4$ & $6: 1$ & $-/ 12$ & $7: 1$ \\
\hline 3 & Chirazyme L-2, C1 & -19 & $1: 1.2$ & $-/ 4$ & $1: 1.4$ & & \\
\hline 4 & Chirazyme L-2, C2 & $-/ 18$ & $5: 1$ & & & & \\
\hline 5 & Amano PS & $-/ 16$ & $1: 8$ & & & & \\
\hline 6 & Amano PS ${ }^{\mathrm{a}}$ & 19/- & $1: 8$ & $-/ 4$ & $1.4: 1$ & -17 & $\underline{267: 1}$ \\
\hline 7 & SP 430 & $67 /-$ & $5.4: 1$ & $-/ 5$ & $3: 1$ & & \\
\hline 8 & Candida cylindracea $a^{\mathrm{a}}$ & $-/ 46^{\mathrm{b}}$ & $1.6: 1$ & & & & \\
\hline 9 & Pseudomonas cepacia ${ }^{\mathrm{a}}$ & $-146^{\mathrm{b}}$ & $1: 3$ & & & & \\
\hline 10 & Hog pancreas ${ }^{\mathrm{a}}$ & $-/ 18$ & $1: 1.1$ & & & & \\
\hline 11 & Mucor miehei ${ }^{\mathrm{a}}$ & $-146^{\mathrm{b}}$ & $1: 3$ & & & & \\
\hline
\end{tabular}

${ }^{\mathrm{a}}$ For immobilized enzyme.

${ }^{\mathrm{b}}$ For conversion $<100 \%$.

In accordance with our expectation, changes in enzyme influenced the stereoselectivity and kinetics of desymmetrization. Only one nonimmobilized enzyme, Amano PS, catalyzed this reaction efficiently, but the reaction time, 16 days, is much longer than that for immobilized Amano PS enzyme $(19 \mathrm{~h})$. The use of other immobilized enzymes changed the stereoselectivity of reaction (entries 1 and 2 vs. 5 and 6) for phenylglutaric anhydride. Also, the remarkable influence of substituents on the phenyl ring (4- $\mathrm{Cl}$ for $\mathbf{5 b}, 4-\mathrm{OMe}$ for $\mathbf{5 c}$ ) is evident. For the same Amano PS enzyme, the enantiomeric ratio changed from 1:1 to $1.4: 1$ and $267: 1$ upon substituent change.

\section{COMBINATION OF ENZYMATIC DESYMMETRIZATION WITH UGI 4CC CONDENSATION}

Enzymatic desymmetrization of 3-phenylglutaric anhydrides can readily be performed in ethereal solvents with good stereoselectivity and in high yield. Products of these reactions, chiral monoesters $\mathbf{5}$, can be used as substrates for subsequent MCCs. Unfortunately, MCC proceeds in other solvents. Our initial idea of combining Ugi 4CC condensation with enzymatic desymmetrization is based on the assumption that both experiment procedure can be performed simultaneously, in the same solvent, from anhydrides 4 to compounds 6, shown in Scheme 4.

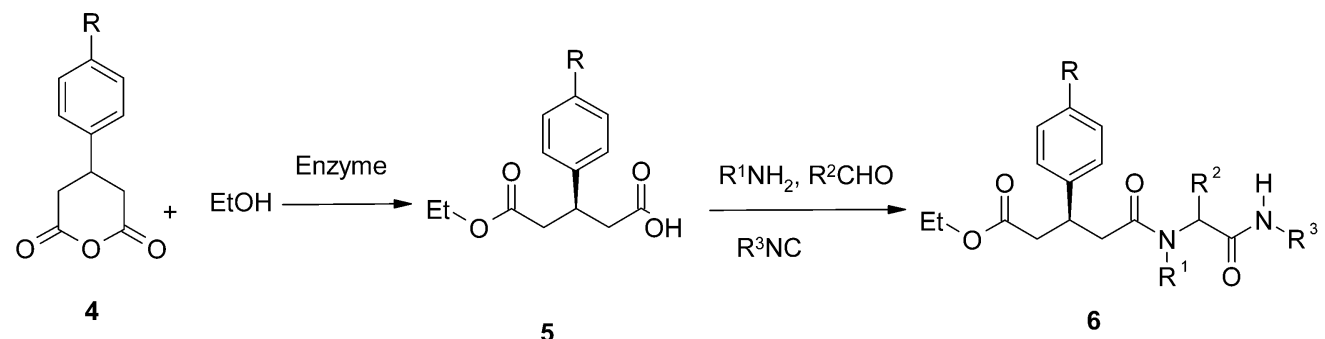

Scheme 4 Combination of enzymatic desymmetrization with Ugi condensation. 
Initially, we tried to perform the Ugi reaction in ethereal solvents on racemic acid 5a and for butylamine, 2-naphthaldehyde, and ethyl isocyanoacetate as other reagents (entry 1 in Table 3). Reaction did not occur. Addition of alcohol was necessary to complete the reaction. In a mixture of isopropyl ether-methanol (2:1), reaction proceeds in $24 \mathrm{~h}$ and the desired product was obtained in $6 \%$ yield (entry 2 in Table 3). Reaction of chiral acid 5a and benzylamine proceeds in the same yield (entry 3 in Table 3). In the next experiment, enzymatic desymmetrization of anhydride $4 \mathbf{a}$ was coupled with an Ugi MCC. Crude acid 5a was directly used for the next reaction, and the final product was obtained in $13 \%$ yield (entry 3 in Table 3 ). This two-step, one-pot approach increased the yield of reaction from 6 to $13 \%$. The product obtained consists of syn/anti diastereoisomers, in a 1:1 ratio on the newly formed asymmetric center, as evidenced by NMR data. This is a common feature of Ugi condensation, and is caused by epimerization $\alpha$ - to the formyl group [20]. Better yields were obtained for $p$-bromobenzaldehyde and butyl- and benzylamines (entries 4 and 5 in Table 3) and our two-step, one-pot approach leads to formation of desired product in almost the same yield as in two separate reactions.

Table 3 The synthesis of products 6.

\begin{tabular}{|c|c|c|c|c|c|c|c|}
\hline Entry & Acid 3 & $\mathrm{R}^{1}$ & $\mathrm{R}^{2}$ & $\mathrm{R}^{3}$ & Solvent & Yield $^{\mathrm{a}}$ & $\operatorname{Yield}^{\mathrm{b}}\left(\mathrm{d}_{\mathrm{r}}\right)$ \\
\hline 1 & $5 \mathbf{a}$ & $n-\mathrm{Bu}$ & 2-Naph & $\mathrm{CH}_{2} \mathrm{COOEt}$ & $\mathrm{C}$ & 0 & \\
\hline 2 & $5 \mathbf{a}$ & $n-\mathrm{Bu}$ & 2-Naph & $\mathrm{CH}_{2} \mathrm{COOEt}$ & $\mathrm{D}$ & 6 & \\
\hline 3 & $\mathbf{5 a},(S)$ & $n-\mathrm{Bn}$ & 2-Naph & $\mathrm{CH}_{2} \mathrm{COOEt}$ & $\mathrm{D}$ & 6 & 13 \\
\hline 4 & 5a, $(S)$ & $n-\mathrm{Bn}$ & $p$-Br-Ph & $\mathrm{Bn}$ & $\mathrm{D}$ & 23 & 25 \\
\hline 5 & $\mathbf{5 a},(S)$ & $n-\mathrm{Bu}$ & $p-\mathrm{Br}-\mathrm{Ph}$ & $\mathrm{Bn}$ & $\mathrm{D}$ & 32 & 31 \\
\hline 6 & 5a, $(S)$ & $n-\mathrm{Bu}$ & $i-\mathrm{Bu}$ & $\mathrm{CH}_{2} \mathrm{COOEt}$ & $\mathrm{D}$ & 49 & $49(1.6: 1)$ \\
\hline 7 & $5 \mathbf{a}$ & $n-\mathrm{Bu}$ & $i-\mathrm{Bu}$ & $\mathrm{Bn}$ & $\mathrm{D}$ & 82 & \\
\hline 8 & 5a, $(S)$ & $n-\mathrm{Bu}$ & $i-\mathrm{Bu}$ & $\mathrm{Bn}$ & $\mathrm{D}$ & 67 & $81(1.25: 1)$ \\
\hline 9 & $\mathbf{5 a},(S)$ & $n-\mathrm{Bn}$ & $i$-Bn & $\mathrm{Bn}$ & $\mathrm{D}$ & 80 & 29 \\
\hline 10 & $\mathbf{5 b},(S)$ & $n-\mathrm{Bu}$ & $i-\mathrm{Bu}$ & $\mathrm{Bn}$ & $\mathrm{D}$ & 70 & $53(1.1: 1)$ \\
\hline 11 & $\mathbf{5 c},(S)$ & $n-\mathrm{Bu}$ & $i-\mathrm{Bu}$ & $\mathrm{Bn}$ & D & 72 & $59(2: 1)$ \\
\hline
\end{tabular}

${ }^{\mathrm{a}}$ For Ugi reactions on racemic $\mathbf{5}$.

${ }^{\mathrm{b}}$ For two-step, one-pot reactions; tandem enzymatic desymmetrization-Ugi processes.

${ }^{\mathrm{c}}$ Isopropyl ether.

${ }^{\mathrm{d}}$ Isopropyl ether: methanol, 2:1, v/v.

It is known that Ugi condensation is sensitive toward carbonyl reagent. A two-step approach leads to formation of a 1:1 diastereoisomeric mixture of products $\mathbf{6 a}$ for isovaleraldehyde in $49 \%$ yield (entry 6 in Table 3). Our two-step, but one-pot approach did not change the yield of reaction, but a moderate change in diastereoselectivity was observed from 1:1 to 1.6:1. NMR data revealed that anti-diastereoisomers predominate.

It is interesting to note that the Ugi reaction of racemic acid 5a proceeds in $82 \%$ yield (entry 7 in Table 3). The same, but chiral, product was obtained in lower, $67 \%$ yield, in a two-step process. Our two-step, one-pot process proceeds in $81 \%$ yield, similar to that for Ugi reaction of racemic acid (entries 7 and 8 in Table 3). Desymmetrization of anhydrides possessing chloro and methoxy substituents $\mathbf{4 b}$ and $\mathbf{4 c}$ combined with Ugi condensation is straightforward, and the respective products 6 obtained in two-step, one-pot methodology were formed in slightly lower yield (entries 9 and 10 in Table 3). Again, in both cases, anti-diastereoisomers predominate.

Combination of enzymatic desymmetrization with Ugi 4CC condensation proceeds efficiently, and in most cases, the yield of one-pot processes are similar to those obtained in separate sequential reactions. It is interesting to note that incorporation of enzymes for the desymmetrization reaction gave rise to some diastereoselectivity during the subsequent Ugi condensation. 


\section{COMBINATION OF ENZYMATIC DESYMMETRIZATION WITH PASSERINI 3CC CONDENSATION}

Our initial idea on combination of Passerini 3CC condensation with enzymatic desymmetrization is also based on the assumption that both experiment procedures can be performed simultaneously, in the same solvent, from anhydrides $\mathbf{4}$ to compounds $\mathbf{7}$, as shown in Scheme 5.

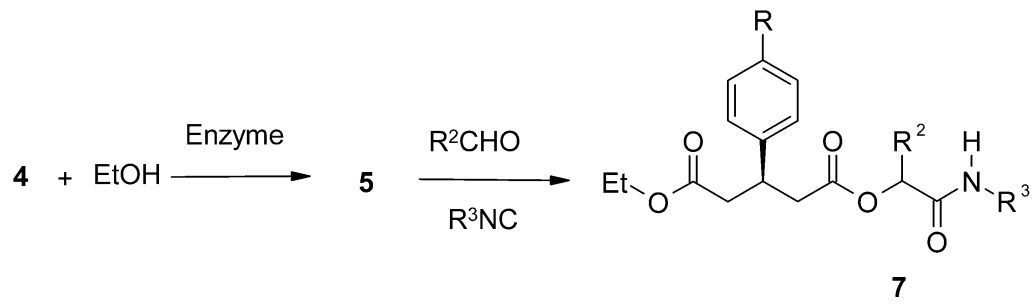

Scheme 5 The synthesis of product 7 .

Model studies performed on racemic acid 5a indicated that addition of alcohol to isopropyl ether as cosolvent is required for the Passerini reaction (entries 1 and 2 in Table 4). In contrast to the Ugi reaction, methanol cannot be used, since some transesterification of products 7 was observed.

Table 4 The synthesis of products 7.

\begin{tabular}{llllcccc}
\hline Entry & Acid $\mathbf{5}$ & $\mathrm{R}$ & \multicolumn{1}{c}{$\mathrm{R}^{2}$} & $\mathrm{R}^{3}$ & Solvent & Yield $^{\mathrm{a}}(\%)$ & Yield $^{\mathrm{b}}(\%)$ \\
\hline 1 & $\mathbf{5 a}$ & $\mathrm{H}$ & $\mathrm{Et}$ & $\mathrm{Bn}$ & $\mathrm{C}$ & 39 & \\
2 & $\mathbf{5 a},(S)$ & $\mathrm{H}$ & $\mathrm{Et}$ & $\mathrm{Bn}$ & $\mathrm{D}$ & 40 & 41 \\
3 & $\mathbf{5 a},(S)$ & $\mathrm{H}$ & $i$-Bu & $\mathrm{Bn}$ & $\mathrm{D}$ & 41 & 40 \\
4 & $\mathbf{5 b},(S)$ & $\mathrm{Cl}$ & $i$-Bu & $\mathrm{Bn}$ & $\mathrm{D}$ & 35 & 25 \\
5 & $\mathbf{5 a},(S)$ & $\mathrm{H}$ & $i$-Bu & $n$-Hex & $\mathrm{D}$ & 32 & 40 \\
6 & $\mathbf{5 a},(S)$ & $\mathrm{H}$ & $n$-Hept & $\mathrm{Bn}$ & $\mathrm{D}$ & 35 & 36 \\
7 & $\mathbf{5 a}$ & $\mathrm{H}$ & $\mathrm{Ph}$ & $\mathrm{Bn}$ & $\mathrm{D}$ & 18 & \\
\hline
\end{tabular}

${ }^{\mathrm{a}}$ For two-step approach.

${ }^{\mathrm{b}}$ For two-step, one-pot reactions; tandem enzymatic asymmetrization-Passerini processes.

${ }^{\mathrm{c}}$ Isopropyl ether.

${ }^{\mathrm{d}}$ Isopropyl ether: ethanol, 2:1, v/v.

For propionaldehyde and benzyl isocyanate, the desired product 7 was obtained in $40 \%$ yield in two separate reactions (entry 2 in Table 4). Direct combination of enzymatic desymmetrization with Passerini reaction simplifies the operations, and almost the same yield of products was obtained. While the change of isonitrile did not change the overall yield substantially (entries 3 and 5 in Table 4 ) the reaction progress is more sensitive toward carbonyl reagents. For benzaldehyde, the yield drops down to $18 \%$ (entry 7 in Table 4). Addition of enzyme to the reaction did not change the 1:1 syn/anti ratio of diastereoisomers $\mathbf{7}$, in contrast to the outcome of the Ugi reaction.

\section{CONCLUSIONS}

A new synthetic method based on combination of enzymatic desymmetrization of 3-phenylglutaric anhydrides with MCC is proposed. Enzymatic desymmetrization of target compounds can be performed efficiently with full control of the stereochemical course of reaction. Product obtained can be used directly, without separation, for subsequent Ugi and Passerini MCCs. This requires careful choice of reaction solvents. Products can be resolved as diastereoisomers. In most cases, the yield of the two-step, one-pot approach is similar to that of the two-step approach. 
This process is efficient and opens up new possibilities in organic chemistry. According to our knowledge, this is the first example of combination of enzymatic procedures with MCCs.

\section{ACKNOWLEDGMENT}

This work was supported by the Polish State Committee for Scientific Research, Grant 3TO9A 081-19.

\section{REFERENCES}

1. A. S. Ripka and D. H. Rich. Curr. Opin. Chem. Biol. 2, 441 (1998).

2. (a) A. Domling and I. Ugi. Angew. Chem., Int. Ed. 39, 3168 (2000); (b) H. Bienayme, C. Hulme, G. Oddon, P. Schmidt. Chem. Eur. J. 6, 3321 (2000).

3. (a) I. Ugi, A. Domling, B. Werner. J. Heterocycl. Chem. 37, 647 (2000); (b) C. Hulme, J. Peng, S.-Y. Tang, C. J. Burns, I. Morize, R. Labaudiniere. J. Org. Chem. 63, 8021 (1998).

4. (a) D. L. Wright, C. V. Robotham, K. Aboud. Tetrahedron Lett. 43, 943 (2002); (b) K. Beck, M. Magnin-Lachaux, E. Herdtweck, A. Domling. Org. Lett. 3, 2875 (2001).

5. C. O. Kappe. Acc. Chem. Res. 33, 879 (2000).

6. (a) N. A. Petasis, A. Goodman, I. A. Zavialov. Tetrahedron 53, 16463 (1997); (b) B. Jiang, C.-G. Yang, X.-H. Gu. Tetrahedron Lett. 42, 2545 (2001).

7. D. Obrecht and J. M. Villalgordo. Solid-Supported Combinatorial and Parallel Synthesis of Small-Molecular-Weight Compound Libraries, Vol. 17: Tetrahedron Organic Chemistry Series, Chaps. 1 and 4, Pergamon, New York (1998).

8. D. E. Portlock, R. Ostaszewski, D. Naskar, L. West. Tetrahedron Lett. 44, 603 (2003).

9. P. A. Wender, S. T. Handy, D. L. Wright. Chem. Ind. 765 (1997).

10. G. Jung. Combinatorial Chemistry, Chaps. 1 and 4, Wiley-VCH, Weinheim (1999).

11. E. Schoffers, A. Golebiowski, C. R. Johnson. Tetrahedron 52, 3769 (1996).

12. U. T. Bornscheuer and R. J. Kazlaukas. Hydrolases in Organic Chemistry, Chap. 5.2.6, WileyVCH, Weinheim (1999).

13. S. Y. Marvin, I. Lantos, Z. Q. Peng, J. Yu, T. Cacchio. Tetrahedron Lett. 41, 5647 (2000).

14. M. J. Holmann, R. Vail, B. Morgan, V. Sebesan, C. Levy, D. R. Dodds, A. Zaks. Adv. Synth. Catal. 343, 744 (2001).

15. (a) K. Yamamoto, T. Nishioka, J. Oda. Tetrahedron Lett. 29, 1717 (1988); (b) Y. Yamamoto, M. Iwasa, S. Sawada, J. Oda. Agric. Biol. Chem. 54, 3269 (1990).

16. (a) R. Ozegowski, A. Kunath, H. Schick. Lieb. Ann. Chem. 1019 (1994); (b) R. Ozegowski, A. Kunath, H. Schick. Lieb. Ann. Chem. 1699 (1995).

17. R. Ozegowski, A. Kunath, H. Schick. Lieb. Ann. Chem. 1443 (1996).

18. A. L. Paiva, V. M. Balcao, F. X. Malcata. Enzyme Microb. Technol. 27, 187 (2000).

19. M. Sato, S. Nagashima, T. Furuya, C. Kaneko. Chem. Pharm. Bull. 40, 1972 (1992).

20. C. L. Kelly, K. W. M. Lawrie, P. Morgan, C. L. Willis. Tetrahedron Lett. 41, 8001 (2000). 